\title{
Effects of tongue electrical stimulation on pharyngeal mechanics in anaesthetized patients with obstructive sleep apnoea
}

\author{
S. Isono, A. Tanaka, T. Nishino
}

Effects of tongue electrical stimulation on pharyngeal mechanics in anaesthetized patients with obstructive sleep apnoea. S. Isono, A. Tanaka, T. Nishino. (C)ERS Journals Ltd 1999. ABSTRACT: The tongue plays a significant role in the maintenance of a patent airway. The purpose of this study was to examine the effects of tongue musculature contraction on the static mechanical properties of the pharynx in patients with obstructive sleep apnoea (OSA).

During hyperventilation-induced apnoea in seven OSA patients anaesthetized with sevoflurane, the static pressure/area relationships of the oropharynx were obtained by means of step changes in airway pressure while endoscopically measuring crosssectional area. At each airway pressure, the tongue was electrically stimulated via electrodes placed bilaterally.

Tongue electrical stimulation (TES) did not further dilate the oropharyngeal area at higher airway pressure $\left(3.2 \pm 1.9\right.$ versus $\left.3.0 \pm 2.1 \mathrm{~cm}^{2}\right)$, although the narrowed oropharyngeal area at lower airway pressures increased during TES $(0.8 \pm 9.0)$ versus $1.7 \pm 1.8$ $\left.\mathbf{c m}^{2}, \mathbf{p}<0.05\right)$. Accordingly, the slope of the pressure/area relationship decreased during TES $\left(0.24 \pm 0.20\right.$ versus $\left.0.12 \pm 0.09 \mathrm{~cm}^{2} \cdot \mathrm{cmH}_{2} \mathrm{O}^{-1}, \mathrm{p}<0.05\right)$.

In conclusion, electrical stimulation of the tongue stiffens the retroglossal airway wall in patients with obstructive sleep apnoea.

Eur Respir J 1999; 14: 1258-1265.
Dept of Anaesthesiology, Chiba University School, Chiba, Japan.

Correspondence: S. Isono, Dept of Anaesthesiology, Chiba University School of Medicine, 1-8-1 Inohana-cho, Chuo-ku, Chiba 260-8670, Japan Fax: 81432243830

\section{Keywords: Compliance}

electrical stimulation

obstructive sleep apnoea

pharynx

static mechanics

upper airway

Received: February 251999

Accepted after revision August 61999
Reduction of pharyngeal muscle activity unmasks abnormally high collapsibility of the pharynx leading to significant narrowing or complete closure of the pharynx during sleep in patients with obstructive sleep apnoea (OSA), whereas augmented activity of the pharyngeal muscles appears to compensate for the anatomical abnormalities in order to maintain a patent airway during wakefulness [13]. Although there is no doubt that pharyngeal muscles play a significant role in maintaining pharyngeal airway patency, the primary function of the contraction of these muscles has yet to be sufficiently investigated in humans.

Although a number of previous studies have reported an increase in whole hypoglossal nerve activity in response to hypoxia and hypercapnia [4-6], FuLLER et al. [7] simultaneously recorded electromyograms of both tongue protrudor and retractor muscles in an anaesthetized rat preparation, and found that there was coactivation of both muscles during chemoreceptor stimulation. SCHWARTZ et al. [8] reported that pharyngeal collapsibility, assessed by means of the upper airway critical pressure ( $P$ crit), was decreased by electrical stimulation of the whole hypoglossal nerve in anaesthetized cats with isolated upper airways. More recently, HiDA et al. [9] examined the effects of electrical stimulation of the whole hypoglossal nerve on the upper airway pressure/volume relationship in anaesthetized dogs, and found that the slope of the relationship, i.e. the compliance of the upper airway, decreased with the electrical stimulation. These animal studies strongly suggest that both the tongue protrudor and retractor muscles act as stiffeners of the pharynx for airway maintenance, regulating the compliance of the pharyngeal wall. Although EISELE et al. [10] also demonstrated that electrical stimulation of the main trunk of the hypoglossal nerve improved maximum inspiratory airflow in sleeping patients with OSA, there is no direct evidence indicating that coactivation of the tongue protrudor and retractor muscles stiffens the pharyngeal airway wall in unconscious humans. Accordingly, this study was designed in order to test the hypothesis that electrical stimulation of both the tongue protrudor and retractor muscles decreases the compliance of the retroglossal airway wall in anaesthetized patients with OSA.

\section{Materials and methods}

\section{Subjects and overnight oximetry}

Seven male patients with OSA who chose uvulopalatopharyngoplasty as a treatment for their apnoea were included in this study. All had histories of excessive daytime sleepiness, habitual snoring and witnessed repetitive apnoea. Sleep-disordered breathing (SDB) was evaluated using a pulse oximeter (Pulsox-5; Minolta, Tokyo, Japan). All subjects were instructed to attach an oximetry finger probe before sleep and to remove the probe upon awakening. Digital readings of arterial oxygen saturation $\left(\mathrm{Sa}, \mathrm{O}_{2}\right)$ and pulse frequency were stored every $5 \mathrm{~s}$ on a memory card. The stored data were displayed on a computer screen to check the quality of the recordings. The computercalculated oxygen desaturation index defined as the number of oxygen desaturations $>4 \%$ from baseline per hour, 
and the percentage of time spent at $S_{\mathrm{a}, \mathrm{O}_{2}}$ of $<90 \%$. Table 1 lists all nocturnal oximetry data and anthropometric characteristics. Although the oximetry evaluation alone does not clarify the nature of the SDB, it is believed that all patients can be safely diagnosed as having OSA based on oximetry results and clinical symptoms.

Informed consents were obtained from all subjects after the aim and potential risks of the study were fully explained to each. The investigation was approved by the Hospital Ethics Committee.

\section{Electrical stimulation of the tongue}

After clearing off secretions on the surface of the tongue, two electrocardiogram electrodes $\left(1 \mathrm{~cm}^{2}\right)$ were attached bilaterally to the tongue at the mucosal fold level, and connected to an electric stimulator (SEN 3201; Nihon Kohden, Tokyo, Japan). The tongue was stimulated with a pulse width of $0.2 \mathrm{~ms}$, frequency of $100 \mathrm{~Hz}$ and burst duration of 2-3 s. The voltage was set at 20-30 V and apparent tongue movement was confirmed by pharyngeal endoscopy during tongue electrical stimulation (TES). Based on the anatomy of the pharyngeal muscles, it was believed that the current applied through these electrodes spread into the tongue protrudors such as the genioglossus as well as the tongue retractors such as the hyoglossus and the styloglossus.

\section{Pharyngeal endoscopy under general anaesthesia}

Preparation of the subjects. The subjects were premedicated with $0.5 \mathrm{mg}$ atropine $30 \mathrm{~min}$ before induction of anaesthesia. Studies were performed with each subject in a supine position on an operating table, with the neck in a neutral position. A modified tight-fitting nasal continuous positive airway pressure or modified anaesthetic nasal mask was fitted on to each subject. The possibility of air leaks between the mask and face was carefully examined, particularly at airway pressurization to $20 \mathrm{cmH}_{2} \mathrm{O}$. General anaesthesia was induced by intravenous administration of thiopentone $\left(4 \mathrm{mg} \cdot \mathrm{kg}^{-1}\right)$, and was maintained by inhalation of $2-4 \%$ sevoflurane in oxygen. $\mathrm{Sa}_{\mathrm{a}} \mathrm{O}_{2}$, electrocardiography and blood pressure were continuously monitored. The subject was hyperventilated at positive pressure through an anaesthetic machine. Electrical stimulation electrodes were placed bilaterally on the tongue as described above and connected to a stimulator. A slim endoscope (FB15H or FB10H; Pentax, Inc., Tokyo, Japan, $3 \mathrm{~mm}$ and $4.5 \mathrm{~mm}$ outside diameter, respectively) was inserted into the nasal mask and naris. The tip of the endoscope was positioned to visualize the velopharynx (VP; retropalatal space) or the oropharynx (OP; retroglossal space). A closed-circuit camera (ETV8; Nisco, Saitama, Japan) was connected to the endoscope and pharyngeal images were recorded on videotape.

Experimental procedure. In order to determine the pressure/area relationship of the pharynx, the anaesthetic machine was disconnected from the nasal mask, which was then connected to a pressure control system capable of accurately producing a constant preselected airway pressure $(P$ aw $)$ ranging $-20-20 \mathrm{cmH}_{2} \mathrm{O}$ in steps of $1 \mathrm{cmH}_{2} \mathrm{O}$. Cessation of mechanical ventilation resulted in apnoea due to hyperventilation and the respiratory depressant effect of sevoflurane. Paw measured by means of a water manometer was immediately increased and maintained at 20 $\mathrm{cmH}_{2} \mathrm{O}$. While the subject remained apnoeic for 2-3 min, $P$ aw was slowly reduced from $20 \mathrm{cmH}_{2} \mathrm{O}$ to the velopharyngeal closing pressure, i.e. the pressure at which the VP was seen to close completely. At each $P$ aw, TES was performed for $\sim 2-3 \mathrm{~s}$. In all subjects, $\mathrm{Sa}_{\mathrm{a}} \mathrm{O}_{2}$ remained $>99 \%$ throughout the test. This hyperventilation-induced apnoea procedure allowed construction of pressure/area relationships of the visualized airway with and without (control) TES. The apnoeic tests were terminated at the restarting of spontaneous breathing or with unexpected movement of the pharyngeal wall. The distance between the endoscope tip and the narrowing site was measured by means of a wire passed through the aspiration channel of the endoscope. The apnoeic tests were performed at the oropharyngeal and velopharyngeal airways.

After evaluation of the influence of TES on the static pressure/area relationship of the pharynx, a completely paralysed condition was induced by intravenous administration of a muscle relaxant (vecuronium $0.2 \mathrm{mg} \cdot \mathrm{kg}^{-1}$ ) allowing evaluation of the static mechanics of the atonic pharynx as previously reported [11]. Briefly, the apnoeic test mentioned above was repeated in this paralysed condition while observing the VP or the OP.

\section{Data analysis}

In order to convert the monitor image to an absolute value of pharyngeal cross-sectional area, the magnification of the imaging system was estimated at every $1.0 \mathrm{~mm}$ distance between the endoscope tip and the object at a range of $10-30 \mathrm{~mm}$. At the defined $P$ aw, the pharyngeal lumen image was outlined on tracing paper $\left(50 \mathrm{~g} \cdot \mathrm{m}^{-2}\right)$, cut out and weighed (ER120; AND, Tokyo, Japan). The area

Table 1. - Patient characteristics and results of oximetry

\begin{tabular}{|c|c|c|c|c|c|c|c|c|}
\hline Patient No. & Age yrs & BMI $\mathrm{kg} \cdot \mathrm{m}^{-2}$ & ODI & events $\cdot h^{-1}$ & CT90 & Baseline $\mathrm{Sa}_{\mathrm{a}} \mathrm{O}_{2} \%$ & Nadir $\mathrm{Sa}_{\mathrm{a}} \mathrm{O}_{2} \%$ & Lowest $\mathrm{Sa}_{\mathrm{a}} \mathrm{O}_{2} \%$ \\
\hline 1 & 40.0 & 31.1 & & 27.7 & 10.0 & 96.1 & 87.2 & 72.0 \\
\hline 2 & 40.0 & 35.7 & & 11.6 & 1.0 & 97.8 & 92.0 & 86.0 \\
\hline 3 & 45.0 & 33.2 & & 63.4 & 72.0 & 94.0 & 80.5 & 44.0 \\
\hline 4 & 51.0 & 28.7 & & 48.1 & 47.0 & 96.5 & 84.5 & 62.0 \\
\hline 5 & 59.0 & 26.9 & & 14.3 & 1.0 & 96.5 & 91.3 & 86.0 \\
\hline 6 & 61.0 & 18.6 & & 7.6 & 0.0 & 98.3 & 92.9 & 85.0 \\
\hline 7 & 53.0 & 27.0 & & 17.1 & 3.5 & 97.2 & 90.4 & 77.0 \\
\hline
\end{tabular}

BMI: body mass index; ODI: oxygen desaturation index, defined as the number of oxygen desaturations $>4 \%$ from baseline per hour; CT90: the percentage of time spent at an arterial oxygen saturation $\left(\mathrm{S}_{\mathrm{a}, \mathrm{O}_{2}}\right.$ of $<90 \%$; nadir $\mathrm{Sa}_{\mathrm{a}} \mathrm{O}_{2}$ : mean of lowest $S_{\mathrm{a}, \mathrm{O}_{2}}$ during desaturation events; lowest $\mathrm{Sa}_{\mathrm{a}} \mathrm{O}_{2}$ : lowest $\mathrm{Sa}_{\mathrm{a}} \mathrm{O}_{2}$ : lowest $\mathrm{Sa}_{\mathrm{a}} \mathrm{O}_{2}$ during recording. 
of the paper was converted to pharyngeal cross-sectional area according to the distance/magnification relationship. For a constant distance, the area measurements were validated to be accurate within $8 \%$ (difference between actual and measured areas: $-0.1 \pm 4.6 \%$, range $6.5--7.6 \%$ ) using known-diameter tubes (4-9 mm inner diameter). In addition, anterior/posterior distance and the lateral width of the airway were also measured in order to evaluate the influence of TES on the shape of the pharyngeal airway.

The measured luminal cross-sectional area was plotted as a function of $P$ aw. The maximum cross-sectional area (Amax) for each condition was determined as the mean of the measured areas at the three highest $P$ aw $(18,19$ and 20 $\left.\mathrm{cmH}_{2} \mathrm{O}\right)$. The minimum cross-sectional area $(A \mathrm{~min})$ was determined at the lowest $P$ aw for each condition. Since the nature of the obtained pressure/area curves of the pharynx in the non-paralysed condition was not necessarily exponential as previously reported for the completely paralysed condition [11], only the pressure/area relationship at the six lowest $P$ aw was assessed using a linear regression model. The quality of the fitting was provided by the coefficient $\mathrm{R}^{2}$ of the regression. The effects of TES on the pressure/area relationship at the lower $P$ aw were assessed via changes in the slope of the model representing com-
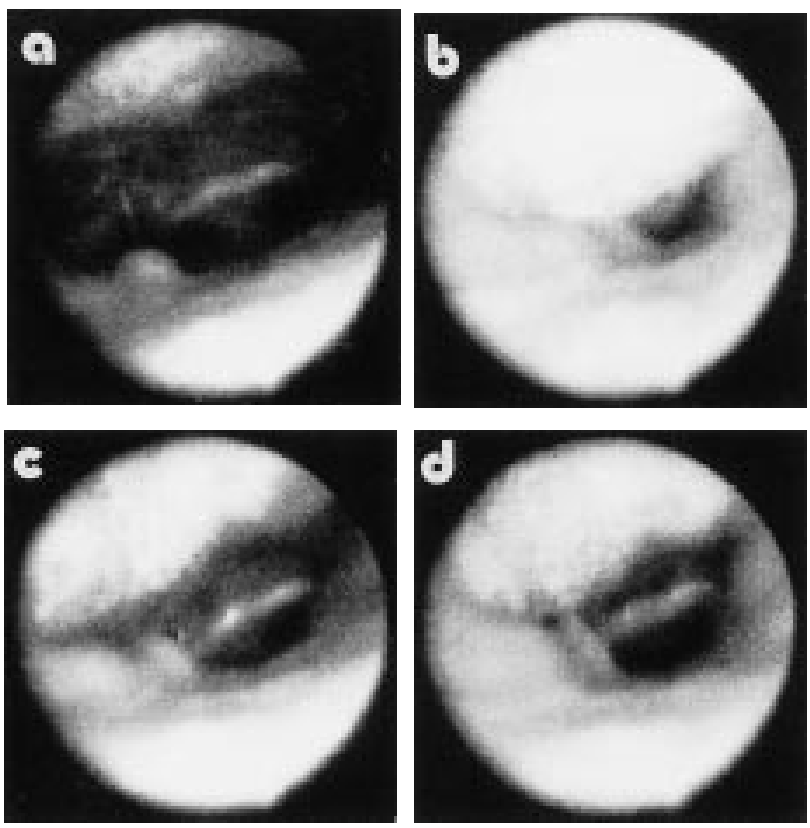

e)

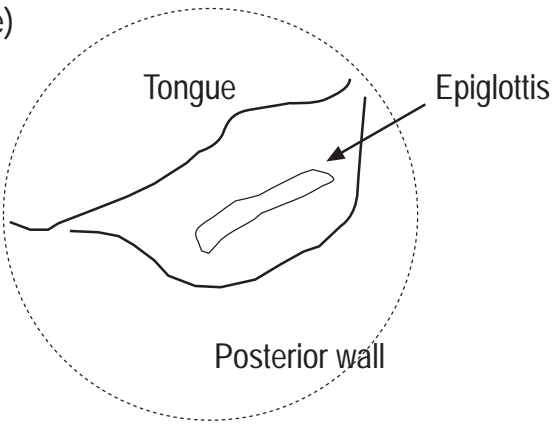

Fig. 1. - Oropharyngeal images: a, b) before (control); and c, d) during tongue electrical stimulation at an airway pressure of: a, c) $20 \mathrm{cmH}_{2} \mathrm{O}$; and b, d) $3 \mathrm{cmH}_{2} \mathrm{O}$ in patient No. 1. e) Diagrammatic representation of $\mathrm{c}$. pliance of the pharynx for the lower $P$ aw range and changes in the $\mathrm{x}$-intercept of the model, representing the closing pressure of the pharynx.

The static pressure/area relationships of the atonic pharynx in the completely paralysed condition were fitted using an exponential function: $A=A \max -B \mathrm{e}^{-K P_{\text {aw }}}$ where $A$ is area and $K$ and $B$ are constants [11]. The closing pressure ( $P$ close) was estimated by $P$ close $=\ln (B / A \max ) K^{-1}$ where $B$ is a constant and the static airway compliance $\left(C_{\mathrm{st}}\right)$ for a given area was calculated from the following equation: $C_{\text {st }}=K(A \max -A)$.

\section{Statistical analysis}

All values are expressed as means $\pm \mathrm{SD}$. The Wilcoxon signed rank test was used for the comparison of control and TES conditions. A p-value $<0.05$ was considered significant.

\section{Results}

Oropharyngeal airway images before and during TES at higher and lower $P$ aw in one patient (No. 1) are shown in figure 1 . TES narrowed the oropharyngeal airway at 20 $\mathrm{cmH}_{2} \mathrm{O}$, but dilated the airway at $3 \mathrm{cmH}_{2} \mathrm{O}$.

\section{Influence of tongue electrical stimulation on pressure/ area relationships of the oropharynx}

The influences of TES on the oropharyngeal pressure/ area relationships in each patient are illustrated in figure 2 . The curves are not exponential, but rather linear. At higher $P$ aw, the cross-sectional area of the OP decreased in four of seven patients (Nos. 1, 2, 3, and 4), remained unchanged in patients No. 5 and No. 6 , and increased in patient No. 7. Amax did not statistically differ before and during TES (fig. 3). In contrast, TES increased the oropharyngeal area at lower $P$ aw except patients No. 4 and No. 6, thereby producing a significant increase in $A$ min (fig. 3). Accordingly, reduction of the slope of the pressure/area relationship was most commonly observed during TES.

\section{Dimensional analyses of the oropharyngeal airway}

The influence of TES on oropharyngeal airway shape was evaluated by measuring anterior/posterior distance and the lateral width of the airway before and during TES. As illustrated in figure 4, TES did not significantly change lateral width at either the higher or the lower $P$ aw. TES significantly increased anterior/posterior distance at lower $P$ aw whereas the distance did not change at higher $P$ aw. Accordingly, TES primarily prevented anterior/posterior narrowing.

\section{Oropharyngeal wall properties at lower airway pressure}

The individual pressure/area relationships of the OP at lower $P$ aw were satisfactorily fitted by linear regression models (mean $\mathrm{R}^{2}$ range $0.94-0.99$ ). The $\mathrm{x}$-intercept before 

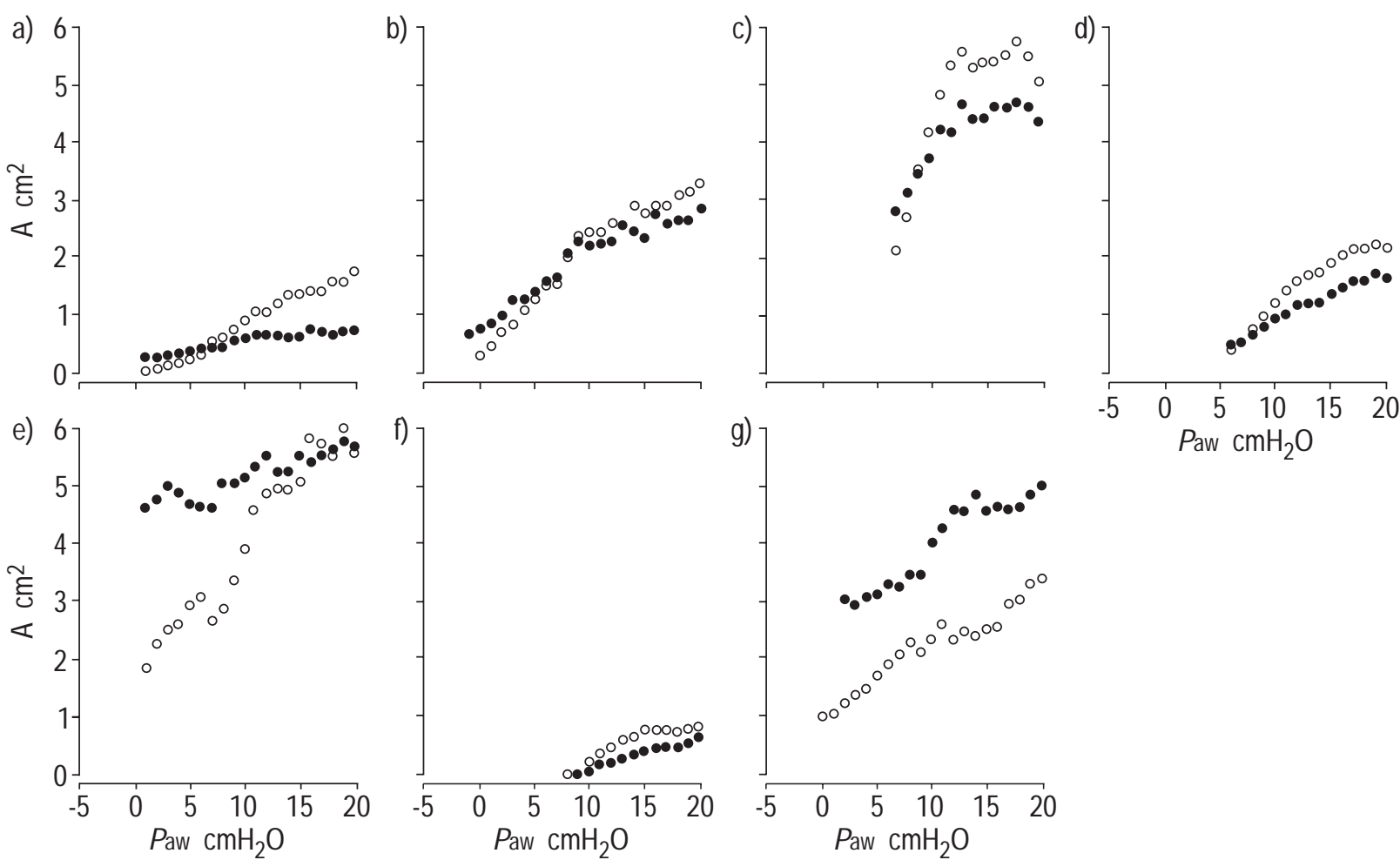

Fig. 2. - Static oropharyngeal pressure/area $(A)$ relationships before (control, $\bigcirc)$ and during tongue electrical stimulation ( No.: a) 1 ; b) 2 ; c) 3 ; d) 4 ; e) 5; f) 6 ; and g) 7 . Paw: airway pressure.

TES $\left(0.43 \pm 5.7 \mathrm{cmH}_{2} \mathrm{O}\right)$ significantly decreased during TES (-12.7 $\left.\pm 20.8 \mathrm{cmH}_{2} \mathrm{O}\right)$ (fig. 5). The slope of the linear regression model $\left(0.24 \pm 0.20 \mathrm{~cm}^{2} \cdot \mathrm{cmH}_{2} \mathrm{O}\right)$ significantly decreased during TES $\left(0.12 \pm 0.09 \mathrm{~cm}^{2} \cdot \mathrm{cmH}_{2} \mathrm{O}\right)$, indicating a reduction in the compliance of the oropharyngeal airway wall during TES. Since the absolute value of the compliance depends upon the size of the airway, the reduction rate of the compliance was calculated. Interestingly, it was found that the reduction rate of the compliance varied little among the patients $(51 \pm 9 \%$ reduction in the slope, 43-69\%). The oropharyngeal compliance decreased by a half during TES in patient No. 6, with the fewest SDB events and the lowest body mass index although the OP significantly narrowed during TES, resulting in an increase in $P$ close in this patient.
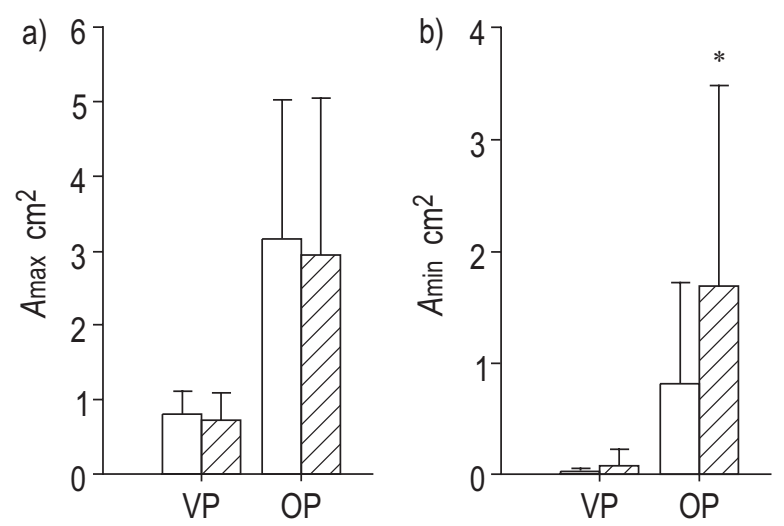

Fig. 3. - Influence of tongue electrical stimulation (TES) on: maximum $(A \max )$; and b) minimum cross-sectional area $(A \min )$ at the velopharynx (VP) and the oropharynx (OP). $\square:$ control; $\mathbb{Z}:$ TES. *: $\mathrm{p}<0.05$ versus control.
Influence of tongue electrical stimulation on the velopharyngeal segment

The influence of TES on the upstream adjacent segment to the OP, i.e. the VP, was variable, and no statistically significant difference was indicated in static mechanical parameters between with and without TES, as shown in figures 3 and 5 . However, it should be noted that the statistical insignificance does not necessarily indicate no influence of TES on static mechanical properties in each of the patients. Figure 6 demonstrates two extreme patterns of velopharyngeal airway responses to TES. The pressure/area relationships of the VP in the control condition (fig. 6) and the responses of the oropharyngeal
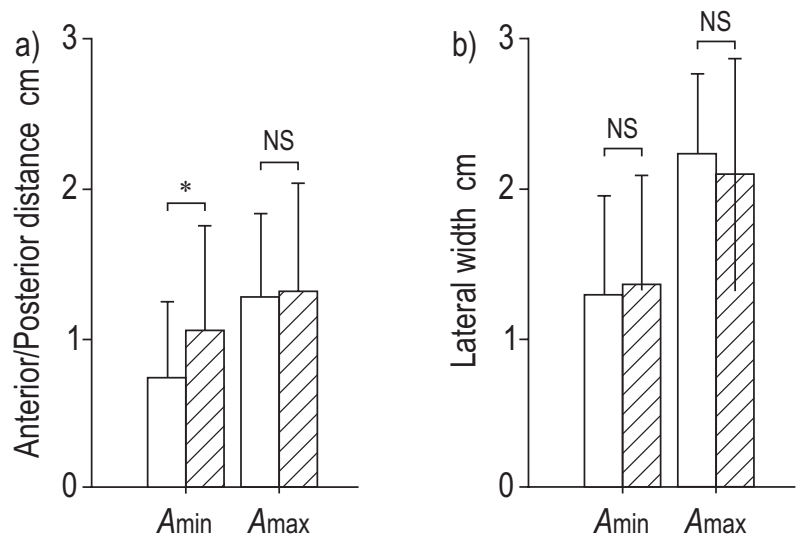

Fig. 4. - Influence of tongue electrical stimulation (TES) on maximally $(A \max )$ and minimally dilated airway $(A \min )$ dimensions of the oropharynx: a) anterior/posterior distance; and b) lateral width. $\square$ : control; $\mathbb{Z}:$ TES. $*$ : $\mathrm{p}<0.05$ versus control. 

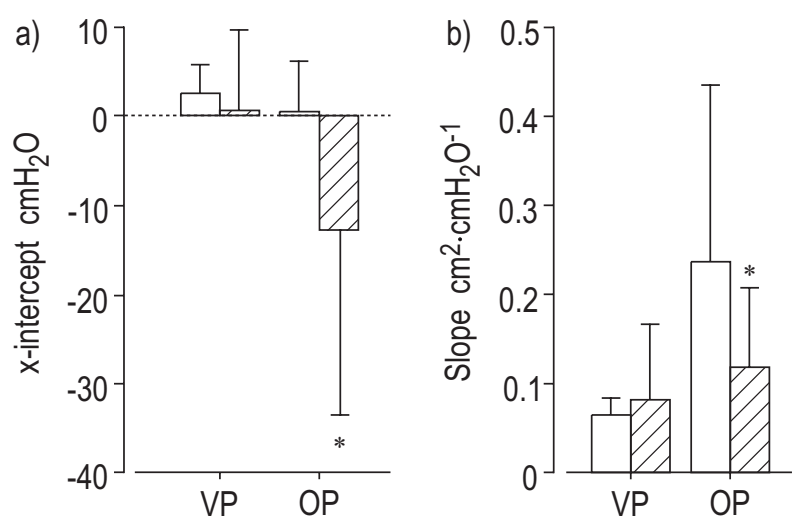

Fig. 5. - Influence of tongue electrical stimulation (TES) on the mechanical characteristics of the velopharynx (VP) and oropharynx (OP) assessed by: a) the $\mathrm{x}$-intercept; and b) the slope of the regression lines of the static pressure/area relationship at lower airway pressures. $\square$ : control; $\mathbb{Z}$ : TES. *: $\mathrm{p}<0.05$ versus control.

segments to TES (fig. 2) were similar between the patients. Nevertheless, the velopharyngeal airway was dilated at the lower $P$ aw and the compliance of the pharyngeal wall was decreased by TES in patient No. 1 whereas TES narrowed the velopharyngeal airway without influencing the compliance of the pharyngeal wall in patient No. 5 .

Static pharyngeal mechanics in the completely paralysed condition

Table 2 presents individual static mechanical parameters obtained in the completely paralyzed condition. Velopharyngeal and oropharyngeal $A$ max in paralysed conditions did not differ from the control $A$ max in nonparalyzed control conditions. Although estimation methods differ between $P$ close and the x-intercept, the individual Pclose for each pharyngeal segment in the paralysed condition was similar to the $\mathrm{x}$-intercept value in nonparalyzed control conditions. The $C_{\text {st }}$ of the OP in the paralysed condition at lower $P$ aw, estimated by $K(A \max -$ $A$ min) did not differ from that in the nonparalyzed control condition, estimated as the slope of the pressure/area relationship at lower $P$ aw, $(0.31 \pm 0.26$ versus $0.24 \pm 0.20$ $\left.\mathrm{cm}^{2} \cdot \mathrm{cmH}_{2} \mathrm{O}\right)$.

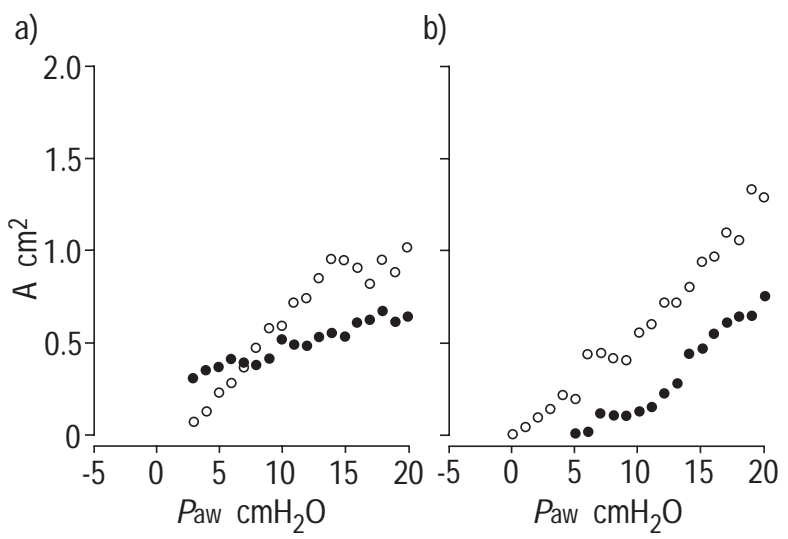

Fig. 6. - Two patterns of the velopharyngeal airway response to tongue electrical stimulation (TES): velopharyngeal area (A) in patients number: a) 1 ; and b) 5 . $\bigcirc$ : control; $\bigcirc$ : TES. Paw: airway pressure.

\section{Discussion}

In this study, it was demonstrated that TES dilated the oropharyngeal area at lower $P$ aw, but not at higher $P$ aw, and that the compliance of the OP assessed by the slope of the pressure/area relationship decreased during contraction of the tongue at lower $P$ aw.

\section{Limitations of the study}

Inhalational anaesthetics are known to depress hypoglossal nerve activity more than phrenic nerve activity [12], and the influence of chemical stimulation of the diaphragm is always greater than that on the upper airway muscles despite differences in the consciousness state. [13]. It was, therefore, believed that the static mechanical properties of the hypotonic pharynx could be evaluated during hyperventilation-induced apnoea under general anaesthesia before initiation of spontaneous breathing. This is supported by the findings that the $P$ close and compliance of the oropharyngeal airway in completely paralysed conditions did not differ from those in nonparalyzed control conditions. However, there is no direct evidence available to deny the suggestion that carbon dioxide accumulation during apnoea might have increased pharyngeal muscle activity since pharyngeal muscle activity was not measured. The control pressure/area relationship of the pharynx obtained in this study may not represent passive mechanical properties, particularly at lower $P$ aw, and the compliance at lower $P$ aw may possibly be underestimated. SchwARTz et al. [14] examined the effects of $\mathrm{CO}_{2}$ accumulation on pharyngeal collapsibility in anaesthetized dogs, and found that an increase in arterial carbon dioxide tension $\left(P \mathrm{a}, \mathrm{CO}_{2}\right)$ of $\sim 10.0 \mathrm{kPa}(\sim 75$ $\mathrm{mmHg}$ ) resulted in a decrease in $P$ crit of $5 \mathrm{cmH}_{2} \mathrm{O}$. In anaesthetized humans, $P \mathrm{a}, \mathrm{CO}_{2}$ is considered to increase by $0.4-0.8 \mathrm{kPa}(3-6 \mathrm{mmHg})$ during an apnoea for $1 \mathrm{~min}$ [15]. During the $2-3 \mathrm{~min}$ apnoeic test in the present study, therefore, $P$ close could be speculated to decrease by $\sim 1$ $\mathrm{cmH}_{2} \mathrm{O}$. The effect of TES on $P$ close were possibly underestimated during the present study, partly due to lack of $P \mathrm{a}, \mathrm{CO}_{2}$ control during the apnoeic tests. In addition, surface adhesive forces on the pharyngeal mucosa may possibly have influenced pressure/area relationships since reopening of the narrowed or closed airway has been reported to be impaired by the mucosal effect [16]. Therefore, the observed dilation of the pharynx during TES at lower $P$ aw may be underestimated, and compliance of the pharynx with TES is possibly overestimated. Accordingly, these uncontrolled factors are considered to alter the pharyngeal pressure/area relationships and to obscure the distinct difference of the pressure/area relationships between passive and active pharynx.

Another limitation of this study would be the lack of evaluation of the dose-dependent effects of TES on static pharyngeal mechanics. Although the stimulation intensity was set based on apparent tongue movement identified by pharyngeal endoscopy, lower intensity stimulation, which is possibly more physiological in terms of the contraction strength of the tongue musculature, could have influences on the pharyngeal wall other than the stiffening effect. 
Table 2. - Static mechanical properties of the pharynx in the paralysed condition

\begin{tabular}{|c|c|c|c|c|c|c|c|}
\hline \multirow[b]{2}{*}{$\begin{array}{l}\text { Patient } \\
\text { No }\end{array}$} & \multicolumn{3}{|c|}{ Velopharynx } & \multicolumn{4}{|c|}{ Oropharynx } \\
\hline & $\underset{\mathrm{cm}^{2}}{A \max }$ & $\begin{array}{c}P \text { close } \\
\mathrm{cmH}_{2} \mathrm{O}\end{array}$ & $\begin{array}{c}C \text { st at } P \text { close } \\
\mathrm{cm}^{2} \cdot \mathrm{cmH}_{2} \mathrm{O}^{-1}\end{array}$ & $A_{\max }^{2}$ & $\begin{array}{c}P_{\text {close }} \\
\mathrm{cmH}_{2} \mathrm{O}\end{array}$ & $\begin{array}{l}C_{\text {st }} \text { at } P \text { close } \\
\mathrm{cm}^{2} \cdot \mathrm{cmH}_{2} \mathrm{O}^{-1}\end{array}$ & $\begin{array}{c}C_{\text {st }} \text { at } A \text { min } \\
\mathrm{cm}^{2} \cdot \mathrm{cmH}_{2} \mathrm{O}^{-1}\end{array}$ \\
\hline 1 & 0.8 & 0.2 & 0.14 & 1.6 & 2.5 & 0.19 & 0.19 \\
\hline 2 & 0.8 & 0.5 & 0.15 & 2.0 & 0.5 & 0.22 & 0.19 \\
\hline 3 & 0.5 & 8.3 & 0.11 & 3.7 & 6.5 & 1.92 & 0.82 \\
\hline 4 & 0.2 & 7.3 & 0.05 & 2.1 & 4.1 & 0.57 & 0.46 \\
\hline 5 & 1.0 & -0.2 & 0.13 & 3.9 & -2.3 & 0.46 & 0.24 \\
\hline 6 & 0.8 & 2.4 & 0.17 & 1.0 & 6.4 & 0.23 & 0.23 \\
\hline 7 & 1.0 & 2.4 & 0.09 & 1.2 & -25 & 0.17 & 0.03 \\
\hline Mean & 0.72 & 3.0 & 0.12 & 2.2 & -1.1 & 0.54 & 0.31 \\
\hline SD & 0.29 & 3.4 & 0.04 & 1.1 & 11 & 0.63 & 0.26 \\
\hline
\end{tabular}

$A$ max: maximum cross-sectional area $(A)$ determined as the mean of the measured areas at the three highest airway pressures $(P$ aw $)(18$, 19 and $\left.20 \mathrm{cmH}_{2} \mathrm{O}\right)$; $P$ close: closing pressure estimated by $\ln (B / A \max ) K^{-1}$ where $K$ and $B$ are constants obtained via curve fitting analysis $\left(A=A \max -B \mathrm{e}^{-K P_{\text {aw }}}\right) ; C$ st: static airway compliance calculated as $C \mathrm{st}=K(A \max -A) ; A \min$ : minimum cross-sectional area observed during apnoeic test.

\section{Mechanical influences of co-activation of the tongue protrudor and the retractor muscles}

The tonic as well as the phasic activities of the genioglossus, a major tongue protrudor muscle, significantly depend upon consciousness state, and a reduction in the activities has been reported to be associated with an increase in upper airway resistance or obstructive apnoea, particularly in patients with OSA $[1,2]$. Recently, КоваYASHI $e t$ al. [17] examined the relationship between genioglossus activity and tongue movement in laryngectomized subjects who breathed through a tracheal stoma, therefore eliminating the effects of $P$ aw on tongue position. They found that increased genioglossal activity enlarged the retroglossal airway space. Based on this evidence, the primary function of the genioglossus in breathing has been believed to be as a dilator of the pharynx. FREGOSI and coworkers [7, 18], however, questioned the simple dilator theory and proposed that the coactivation of tongue protrudor and retractor muscles was important in regulating the compliance of the pharyngeal wall since they found an increase in tongue retraction force during coactivation of the tongue muscles. Their idea was in complete agreement with the results of other previous animal studies evaluating the effects of electrical stimulation of the whole hypoglossal nerve on upper airway collapsibility $[8,9]$. In this context, consideration of possible coactivation of the tongue retractor muscles might give new insights into the interpretation of previous human studies, in which only protrudor muscle activity was measured. The observed anterior movement of the tongue in the study of KoBayashi et al. [17] could have resulted from a balance between tongue protrudor and retractor muscles during mechanical loading. EISELE et al. [20] reported that electrical stimulation of the whole hypoglossal nerve increased maximum inspiratory flow in association with tongue retraction in patients with OSA during sleep. SCHWARTZ et al. [19] further demonstrated that electrical stimulation of the tongue protrudor increased maximum inspiratory flow, whereas electrical stimulation of the tongue retractor decreased maximum inspiratory flow in sleeping apnoeics. Although these human studies were in agreement with the concept proposed by Fregosi and coworkers $[7,18]$ no study exa- mined the effect of coactivation of the tongue muscles on pharyngeal wall properties in humans. Accordingly, examination of the precise mechanical influences of coactivation of the tongue protrudor and retractor muscles may answer the important question as to whether the primary mechanical function of the tongue muscles is dilation of the retroglossal airway or stiffening the airway wall in humans [20]. In a static pressure/area relationship, a simple dilating effect would result in a shift of the curve to the left without changing the slope of the curve, but an increase in the area for a given $P$ aw. In contrast, stiffening of the airway would be determined by a decrease the slope of the curve. Both dilation and stiffening effects were found at lower $P$ aw. The authors believe that dilation and stiffening of the airway are not mutually exclusive, but rather compatible, as clearly shown by the changes in static pressure/area relationships (fig. 2).

\section{Anatomical consideration of tongue movement during tongue electrical stimulation}

Although previous animal and human studies found tongue retraction during coactivation of the protrudor and retractor muscles, significant dilatation of the retroglossal airway was observed during the present study at lower $P$ aw during TES. The position of the tongue is considered to be determined by the balance of contraction force between the tongue protrudor and the retractor muscles. The anatomical arrangement of these muscles in the airway and their force/ length relationship may possibly account for the seeming disagreement between the present findings and previous observations. Fuller et al. [7] measured tongue force while pulling the tongue forward, indicating that retroglossal airway space was not decreased. Since EIsele et al. [10] gave positive nasal airway pressure, maintaining stable inspiratory flow limitation during electrical stimulation of the hypoglossal nerve, the pharyngeal airway was not significantly narrowed at the onset of the stimulation. All these experimental settings are considered to lengthen the retractor muscle fibres, and, therefore, favour retraction of the tongue during coactivation of the protrudor and retractor muscles. In contrast, significant dilatation of the retroglossal airway during TES was observed in the present study only when the genioglossus muscle fibres were considered to be lengthened in 
significantly narrowed or closed airway at lower $P$ aw. Accordingly, coactivation of the protrudor and retractor muscles would cause narrowing of the retroglossal airway in an already dilated airway and cause dilatation of the airway in a significantly narrowed airway.

\section{Interaction between the oropharynx and the velopharynx}

Although no consistent influence of TES on the velopharyngeal pressure/area relationship was found in the present study, TES certainly modulated the mechanical properties of the VP supporting the notion of SCHWARTZ et al. [19]. Considering the anatomical arrangement of the OP and VP, interaction between the two segments can be speculated during TES. First, electric current may stimulate the palatoglossus muscle fibres, which influence velopharyngeal airway size and compliance. Secondly, mechanical connection between the segments through the palatoglossal arch possibly allows movement of the soft palate together with the tongue base. Thirdly, the tongue may have gravitational impact on the soft palate, the anterior wall of which attaches to the base of the tongue. Further studies are necessary for clarification of the mechanisms since the VP is the most common site of occlusion in patients with OSA during sleep [21], and, therefore, successful treatment of OSA by electrical stimulation may depend on the response of the velopharyngeal airway to the stimulation.

\section{Clinical implication of the study}

Since MiKi et al. [22] successfully reversed OSA by submental electrical stimulation, electrical stimulation of the upper airway muscles has been proposed as a possible new therapeutic approach to OSA. Succeeding studies in other laboratories, however, failed to obtain favourable responses to the procedure, although methodological differences exist among the studies [23-25]. The major criticisms include that electrical stimulation of the upper airway possibly resulted in restoration of a patent airway as a result of an arousal response to painful stimulation rather than the direct effect of electrical stimulation on the pharyngeal muscles. The technical difficulty in recording cortical activity during electrical stimulation has limited further examination of the possible contribution of the arousal response to airway patency. In this context, SCHWARTZ et al. [19] successfully stimulated the genioglossus only during inspiration without arousal by placing the electrodes into the musculature away from sensory nerves, and demonstrated an improvement in airflow dynamics as well as a reduction in the number of obstructive episodes in patients with OSA. In accordance with the results of SCHWARTz et al. [19], the present study demonstrated that electrical stimulation of the tongue musculature improved pharyngeal collapsibility without interference from nonspecific activation of the genioglossus in association with cortical arousal. The results, however, may not indicate that electrical stimulation of the upper airway is a useful alternative treatment for OSA since whether the intensity of the applied electrical stimulation level would not cause cortical arousal during natural sleep was not evaluated. Upper airway characteristics evaluated during the experimentally-induced apnoea in anaesthetized patients might differ from those during apnoeas in natural sleep.
In conclusion, contraction of the tongue musculature induced by electrical stimulation stiffened the oropharyngeal airway wall.

Acknowledgements. The authors express great appreciation to T. Takishima and T. Takahashi of the Chest Institute of Technology, Chest Corporation, Miyagi, Japan for their technical assistance. S. Shimizu greatly helped to improve this manuscript.

\section{References}

1. Remmers JE, DeGroot WJ, Sauerland EK, Anch AM. Pathogenesis of upper airway occlusion during sleep. $J$ Appl Physiol 1978; 44: 931-938.

2. Mezzanotte WS, Tanjel DJ, White DP. Influence of sleep onset on upper airway muscle activity in apnoea patients versus normal controls. Am J Respir Crit Care Med 1996; 153: $1880-1887$.

3. Mezzanotte WS, Tanjel DJ, White DP. Waking genioglossal electromyogram in sleep apnoea patients versus normal controls: a neuromuscular compensatory mechanism. J Clin Invest 1992; 89: 1571-1579.

4. Weiner D, Mitra J, Salamone J, Cheniack NS. Effect of chemical stimuli on nerves supplying upper airway muscles. J Appl Physiol 1982; 52: 530-536.

5. Hwang JC, Bartlett D Jr, St John WM. Characterization of respiratory-modulated activities of hypoglossal motoneurons. J Appl Physiol 1983; 55: 793-798.

6. St John WM, Knuth KV, Rist KE. Dynamic changes of hypoglossal and phrenic activities by hypoxia and hypercapnia. Respir Physiol 1984; 56: 237-244.

7. Fuller D, Mateika JH, Fregosi RF. Co-activation of tongue protrudor and retractor muscles during chemoreceptor stimulation in the rat. $J$ Physiol (Lond) 1998; 507: 265-276.

8. Schwartz AR, Thut D, Russ DB, et al. Effect of electrical stimulation of the hypoglossal nerve on airflow mechanics in the isolated upper airway. Am Rev Respir Dis 1993; 147: 1144-1150.

9. Hida W, Kurosawa H, Okabe S, et al. Hypoglossal nerve stimulation affects the pressure-volume behavior of the upper airway. Am J Respir Crit Care Med 1995; 151: 455-460.

10. Eisele DW, Smith PL, Schwartz AR. Direct hypoglossal nerve stimulation in obstructive sleep apnoea. Arch Otolaryngol Head Neck Surg 1997; 123: 57-61.

11. Isono S, Remmers JE, Tanaka A, Sho Y, Sato J, Nishino T. Anatomy of pharynx in patients with obstructive sleep apnoea and in normal subjects. $J$ Appl Physiol 1997; 82: 1319-1326.

12. Nishino T, Shirahata M, Yonezawa T, Honda Y. Comparison of changes in the hypoglossal and phrenic nerve activity in response to increasing depth of anesthesia in cats. Anesthesiology 1984; 60: 19-24.

13. Parisi RA, Santiago TV, Edelman NH. Genioglossal and diaphragmatic EMG responses to hypoxia during sleep. Am Rev Respir Dis 1988; 138: 610-616.

14. Schwartz AR, Thut DC, Brower RG, et al. Modulation of maximal inspiratory airflow by neuromuscular activity: effect of $\mathrm{CO}_{2}$. J Appl Physiol 1993; 74: 1597-1605.

15. Nunn JF. Carbon dioxide. In: Nunn JF, ed. Applied Respiratory Physiology, 3rd Edn. London, Butterworths, 1987; pp. 207-234.

16. Wilson SL, Thach BT, Brouillette RT, Abuosba YK. Upper airway patency in human infant: influence of 
airway pressure and posture. J Appl Physiol 1980; 48: 500-504.

17. Kobayashi I, Perry A, Rhymer J, et al. Inspiratory coactivation of genioglossus enlarges the retroglossal space in laryngectomized humans. $J$ Appl Physiol 1996; 80: $1595-1604$.

18. Fregosi RF, Fuller DD. Respiratory-related control of extrinsic tongue muscle activity. Respir Physiol 1997; 110: 295-306.

19. Schwartz AR, Eisele DW, Hari A, Testerman R, Erickson D, Smith PL. Electrical stimulation of the lingual musculature in obstructive sleep apnoea. J Appl Physiol 1996; 81: 643-652.

20. Horner RL. Motor control of the pharyngeal musculature and implications for the pathogenesis of obstructive sleep apnoea. Sleep 1996; 19: 827-853.

21. Morrison DL, Launois SH, Isono S, Feroah TR, Whitelaw WA, Remmers JE. Pharyngeal narrowing and closing pressures in patients with obstructive sleep apnoea. $\mathrm{Am}$ Rev Respir Dis 1993; 148: 606-611.

22. Miki H, Hida W, Chonan T, Kikuchi Y, Takishima T. Effects of submental electrical stimulation during sleep on upper airway patency in patients with obstructive sleep apnoea. Am Rev Respir Dis 1989; 140: 12851289.

23. Edmonds LC, Daniels BK, Stanson AW, Sheedy PF II, Shepard JW Jr. The effects of transcutaneous electrical stimulation during wakefulness and sleep in patients with obstructive sleep apnoea. Am Rev Respir Dis 1992; 146: 1030-1036.

24. Decker MJ, Haaga J, Arnold JL, Atzberger D, Strohl KP. Functional electrical stimulation and respiration during sleep. J Appl Physiol 1993; 75: 1053-1061.

25. Guilleminault C, Powell N, Bowman B, Stoohs R. The effect of electrical stimulation on obstructive sleep apnoea syndrome. Chest 1995; 107: 67-73. 